\title{
GEOGRAPHIC PATTERNS OF CHOICE AMONG PEERS
}

\author{
A. BLAIVAS" AND M. KOCHEN** \\ Wental Health Research Institnte, liniversity of Wichigan \\ R. CRICKMAN $\dagger$ \\ Liniersity of Mimmesola
}

\begin{abstract}
Editors of kes joumals in six specialties were asked to name experts in the ir specialty liom whom they would like to receive manuscripts and whom they would like to use as referees. The people so named were asked for their choice of experts, and similarly for the persons they nominated. The analysis of geographical factors revealed a similarity between nominations and citations. Most of the nominees were from the L.S., followed by the UK and other industrialized and traditionally scientific nations. The U,S. scientists have a higher probability of being nominated than the in proportion in the world scientific population might suggest. Nominators in most of the countries had a distinctive prelerence for nominating their own countrymen, with the exception of the Soviet Union.
\end{abstract}

\section{INTRODUCTION}

The peer review process is of interest to both information scientists and social scientists. It plays a crucial role in maintaining the self-comecting nature of

"Alex Blaivas, principal author, is a Research Associate at the Mental Health Research Institue, L'niversity ol Mishigan. In addition to the mathematical modelling of processes for the growh of science, his professional interests indude computer and experimental investigation of the batin and information processing systems, e.g. mathematical and numcrical modelling of neurophysiological and psychophysical processes of visual perception and exemovements.

* Manfred Kochen is Protessor of Information Science and Research Scientist at the Mental Health Research Institute, University of Michigan, and a nember of the Inban/Regional Planning faculw. He is Managing Editor of Human Systems Management and has written and edited a number of books, most recently Decentralization: Sketches Tondard a Rational Themy (1980), with Karl W. Deutsch.

† Robin Crickman is Assistant Prolessor of Information Science at the University of Minnesota. Her professional interests include computer conferencing, manpower databases, and the relationship of content, structure and achievement in scientific research as mantested by scientific literature. 
science. A scientist's output is information in the scientific literature. Its quality is determined largely by who has the opportunity to do scientific work by virtuc of his or her position and support. High quality papers tend to be published in highly regarded journals. The decisions by a journal to accept or reject a manuscript are usually based on judgments of peers. The network by which peers choose one another, the correlates of peer choice and the effectiveness of the peer selection mechanism are therefore major determinants of the quality of the input to science-based information systems. This includes social science information systems.

Studies of peer interactions are also an important area of inquiry in social science. Peer selection is regarded as a central aspect in the dynamics of science (Ziman, 1978). It has been an object of study in the sociology of science (Lindsey, 1978; Cole and Cole, 1979; Cole et al., 1978).

Among the different factors influencing the choice of peers by editors of $k$ cy journals the factor of geographic and linguistic proximity may play an important role. An editor of a journal in the U.S. may be more likely to choose a countryman for peer review rather than a scientist from a geographically more distant region. However, scientists from a small country that does not have a significant number of specialists in a particular field may choose as peers scientists from other countries. Geographical factors alone do not determine the choice. They may still play a significant role. The effect of geographic proximity upon the choice of peers may be adverse if editors prefer a nearby but mediocre referee to a more distantly located but highiy competent one. In the happy coincidence of the most capable and talented flocking together into close proximity of one another such errors are not likely. If the regional unit of analysis is an entire country, however, this may occur.

Pecr review plays an important role in at least three areas where quality control in science is essential:

(1) maintaining the high selectivity of scientists in academic positions,

(2) awarding research grants,

(3) publication of their research reports in the small number of core journals of their field.

The dynamics governing the formation of peer groups that consist of scientists who regard one another as experts is closely related to the formation of invisible colleges (Price, 1965; Beaver and Price, 1966; Gursey and Price, 1976; Crane, 1972; Kochen, 1974; Ziman, 1980). Its study is closely related to experiments with new ways of selecting referees for manuscripts submitted to a journal (Faegri, 1970; Etzioni, 1971; Zuckerman and Merton, 1971a.b; Manheim, 1973; Ingelfinger, 1974; Noble, 1974; Garvey and Gottfedson, 1976; Kochen and Perkel, 1978). The choice of referees is not 'blind' in the way a jury is ideally selected to serve justice. Nor is it based predominantly on an 'old boy network'. The judgments rendered are about the same when the author submits a list from which the referees are chosen or when the editorial staff chooses them (Abelson, 1980). Editors, however, do, rely on whom they know for sclecting experts to advise them toward acceptance decisions; when an expert chosen by the editor cannot render judgment, he or she will often refer the caller to another expert.

To understand the networks that link experts on the basis of mutual recognition of expertise and interest, we undertook both theoretical and empirical studies. The theoretical approach uses a system of non-lincar differential equations to describe the growth of related specialties (Kochen and 
Blaivas, 1981). Qualitative analysis of these equations shows that the interaction of two specialties may be pictured with the help of a phase portrait of the equation on a phase diagram. In this case the portrait shows some very interesting characteristics allowing us to offer some predictions about the future of these two specialties.

The several features by which we characterize the network empirically will be presented in a series of reports. In this report, we focus on the geographical patterns of peer choices. The general question relates to the possible tendency of experts to choose others who are geographically proximate to them in preference to those who are distant.

\section{METHODOLOGY}

To chart the structure of the network by which such choices of experts and referrals are made, we asked 53 editors of kev journals in six fields to name 10 experts in their field from whom they would like to receive manuscripts and/or whom they would like to use as referees for manuscripts they have recently been receiving. This technique resembles that used by Kadushin in his study of intellectual élite (Kadushin, 1966, 1974) The six fields were: 1) Differential Geometry; 2) Low-dimensional Topology; 3) Information Science; 4) General Systems Theory; 5) Human Systems Management; and 6) Future Studies. The first two are well-defined and related mathematical specialties. Information science is an emerging field, which is quickly becoming an established scientific discipline. Science and Nature have been outlets for some of its results (Ziman, 1980; Goffman and Warren, 1969; Price, 1965). Human Systems Management is the title of a new journal and represents the current stage into which operations research and management science appears to be cvolving. Future Studies is interesting as an example of a discipline which has been most recently developed as having a host of firm connections with many socio-economic and science fields. It was chosen for contrast in the patterns of peer choices. The response from 40 of the 53 editors resulted in 415 nominations to 350 different experts, 104 of whom responded to our second round of mail questionnaires. Among other questions, we asked them to state their main specialty, and a number of them named it to be Polymer Chemistry; thus a seventh field was added to our sample, which now comprised three 'hard' sciences, three 'soft' sciences and a non-science field. It was surprising that scientists who were named by peers in, say, 'Futures Studies' as experts in that field saw themselves to be primarily polymer chemists.

The 104 experts who responded to our second round questionnaire made 1049 nominations of 771 different persons, who were sent third round questionnaires. Of these, 132 responded and made 880 nominations for 701 different nominees. Altogether, 276 different respondents expressed 2400 choices in which 1342 different experts were named, 440 previously unnamed experts are being sent a fourth round questionnaire at this time.

The information from the questionnaire responses was entered into a computer database management system called MICRO in two, interconnected files: one on the individuals who responded to the questionnaire and a second on the individuals whom the respondents nominated. Recorded information about the respondents included unique identity, employer information, geographic locale, and the self-assigned specialty of the respondent. Information on those nominated as experts included unique identity, employer, and geographic locale. 


\section{THE MAIN FINDINGS OF THE STUDY PERTAINING TO GEOGRAPHIC FACTORS}

The geographical distribution of the respondents is shown in Table 1.

TABH: 1

Geographic Distribution of Respondents

\begin{tabular}{|c|c|c|c|c|c|c|c|c|}
\hline$(x+m) m)$ & $\begin{array}{l}\text { Rosund } \\
\text { No.ol } \\
\text { Kespondents }\end{array}$ & " & $\begin{array}{l}\text { Round } \\
\text { Nonol } \\
\text { Rospondens }\end{array}$ & 2 & $\begin{array}{l}\text { Round } \\
\text { No. of } \\
\text { Respomelont. }\end{array}$ & $"$ " & $\begin{array}{c}\text { All Romm } \\
\text { No.of } \\
\text { Revpondents }\end{array}$ & $\begin{array}{l}\text { ds } \\
\text { i. }\end{array}$ \\
\hline Inited States & 29 & 6.5 .90 & 69 & 66.34 & 106 & 80.30 & 204 & $7 \therefore 86$ \\
\hline L !nited Kingelom & 4 & 9.10 & 14 & 13.46 & 6 & $t . i t$ & 21 & 8.57 \\
\hline France & $\because$ & 4.55 & 7 & 6.73 & 2 & 1.51 & 11 & 3.93 \\
\hline Japaall & 0 & & 3 & 2.88 & 5 & 3.78 & $s$ & 286 \\
\hline Germanty & 1 & 2.27 & $j$ & 4.80 & 1 & .75 & 7 & 2.50 \\
\hline Nomwa & 1 & 2.27 & 1 & & 4 & 3.03 & 6) & 2.14 \\
\hline Citnadia & 1 & 2.27 & 1 & & 5 & 3.78 & 7 & 250 \\
\hline Sweden & 0 & 0 & 2 & 1.92 & 1 & .75 & 3 & 1.07 \\
\hline Belgium & 1 & 2.27 & 1 & .96 & 0 & & 2 & .71 \\
\hline Rumania & 1 & 2.27 & 0 & & 0 & & l & .36 \\
\hline Occinial & 0 & 0 & 1 & & 1 & .75 & 1 & .36 \\
\hline Netherlands & 0 & 0 & I & $.96 j$ & 1 & & 1 & .36 \\
\hline Finland & () & 0 & 0 & & 1 & .75 & 1 & .36 \\
\hline
\end{tabular}

29 out of $40(75$ per cent respondents from the first round were American scientists. It is interesting to note that the proportion of the American scientists has been steadily increased from round to round eventually reaching 80.3 per cent in the third round. The reason for this rise may be the intemational visibility of American science, the abundance of publications by American scientists, their rich international connections, and personal contacts with scientists from other countries.

Within the U.S., reputable university towns of small overall population produced more respondents per capita than did some megalopolises. For example, thaca and Stony Brook (both in New York state) gave 43 and 21 respondents respectively, while New York City gave only 72 respondents. Undoubtedly the geographical distribution of respondents and mominees reflects the geographical distribution of scientific productivity and can be used as a measure of the latter.

Table 2 gives the distribution of nominees for all three rounds of the survey for all the countries.

The U.S. ranks highest with nearly $3 / 4$ of all nominations. As before, the British and the French are a distant second to the U.S. Japan has moved from fourth place, supplanted by Canada and Germany.

The prevalence of the nominations of the U.S. scientists may be correlated with recent data on the citation analysis in sociological literature (Line, 1981). Studying the citation links between different countrie's in the field of sociology he found that the U.S. and in lesser degree the UK, accounts for a higher percentage of citation occurrences than might have been expected from their proportion in the general world population. The observation by Line is in line with our finding. Moreover, Line found that in the social sciences most countries' publications tend to cite the local sources. This has been explained by parochialism; as Line said, 
social scientists are much more concerned with local problems than are representatives of 'pure' and 'hard' science, where the international character of problems encourages cross-citations. However, even in social science, the U.S. appears to predominate. It is therefore not surprising to find a similar pattern in peer nominations in fields which might be considered as lying on the boundary between social and the rest of the science.

Frequency analysis of nominations revealed that some people received more than one - sometimes two or three, and up to 17 - nominations. We gave the name 'stars' to scientists receiving eight or more nominations. For nearly all our fields, that was about 3 per cent. Of course, these scientists are all well known in their particular fields. In this geographical study we paid special attention to the andysis of their geographical location (residence) because this is also a characteristic of their national scientific community. It turns out that only the U.S. and UK have more than a few stars. The proportion of stars for the U.S. is about the same as the proportion of overall nominations 71.13 per cent of all stars live in the U.S. as compared with 72.29 per cent of all nominations received by the U.S. scientists).

TABLE 2

Goographical Distribution of Nominees $(2,400$ Nominations on 32 Countries)

\begin{tabular}{|c|c|c|}
\hline $\begin{array}{c}\text { Noot } \\
\text { Nominatlioms }\end{array}$ & Country & Percent \\
\hline 1.735 & United States & 72.79 \\
\hline 233 & United Kingdom & 9.70 \\
\hline 103 & France & 4.29 \\
\hline 56 & Canada & 2.33 \\
\hline 5.5 & Germany & 2.29 \\
\hline 48 & Japan & 2.00 \\
\hline 35 & Others & 1.45 \\
\hline 125 & Norway & 1.04 \\
\hline 14 & Sweden & .58 \\
\hline 14 & Nexherliands & .58 \\
\hline 12 & Denmatk & .50 \\
\hline 10 & Austria & .41 \\
\hline 9 & Belgium & .37 \\
\hline 7 & Orcanial & .29 \\
\hline 6 & Is]atel & .25 \\
\hline$j$ & LSSR & .20 \\
\hline$t$ & Switzerland & .16 \\
\hline 4 & Italy & .16 \\
\hline 4 & Chile & .16 \\
\hline 3 & Rumbania & .12 \\
\hline 3 & Finland & .12 \\
\hline 2 & Yuguslavia & .08 \\
\hline 2 & Spain & .08 \\
\hline$\because$ & Mrxico & .08 \\
\hline 2 & India & .08 \\
\hline 1 & South Atrica & .04 \\
\hline$i$ & Poland & .04 \\
\hline 1 & Luxembourg & .04 \\
\hline$i$ & Kenya & .04 \\
\hline l & Iran & .04 \\
\hline 1 & International & .04 \\
\hline 1 & Corechoslowakia & .04 \\
\hline
\end{tabular}


The general UK share of the nominations is 9.7 per cent while their share of stars is more than 50 per cent larger, 15.46 per cent. Social conditions in Britain may encourage young unrecognized scientists to try to establish themselves in other countries (for example, in Australia and in the U.S.). But prominent scientists may receive adequate support from the government and the public which helps them to stay and develop their research potential. If this is true, the situation may not last for a long while. Sooner or later the lack of fresh minds might show up in a declining proportion of stars as well.

A natural analogue of the study of distribution of nominations is the study of the (geographical, linguistical etc.) distribution of citations in scientific papers and monographs. Therefore we compare the nomination process with the distribution of citations, which is well developed.

Patterns of citation analysis suggest that scientists do not tend to cite literature which is not written by their own countrymen with the frequency that should be expected from simple levels of publication volume (King et al., 1975; Line, 1981). In other words, the closer the source of citation in geographical sense the greater the probability that it may be cited by a given author. One might expect that nomination of experts would also show similar distortions of selection in favour of the scientists of one's own country. To check this conjecture consider Table 3 which shows the extent to which respondents in one country nominate experts in other countries. This table is limited to nations having at least 10 total nominations.

Of these 11 columns and 11 rows in the table, 9 are devoted to the U.S., UK, France, Canada, Germany, Japan, Norway, Sweden, and Netherlands. The 10th column and 10th row are devoted to 'all other countries' except these 9 most productive. The 11 th column and 11 th row are devoted to the total of all the surveyed countries from which our respondents wrote us. Most of the cells lying on the intersection of each row and each column contain one integer and two percentages. The first number or integer is the number of nominations from a respondent in the country designated by the column to nominees in the country specified by the row. The second (upper) number in the same cell is that percentage of the row-country's nominations of all those originating from the column-country. The third (lowest) number is the percentage which represents the proportion of the votes received by the row country from voters of the column-country. In some cells we inserted zeroes because we had no corresponding nominations. For example, the cell in the first column and second row represent the cross-nominations between the U.S. and the UK. The integer 88 gives the number of nominations which have been given by English scientists to the scientists from the U.S. This constitutes 36.36 per cent of all nominations given by the English nominators or respondents (the upper percentage). The same 88 nominations constitute just 5.07 per cent of all nominations given to the U.S. scientists from around the world. This percentage is given in below position in this cell.

Study of this table leads us to conclude that the factor of geographical proximity, at least as aggregated by country, plays an essential role in the crossnominations, although sometimes not in straightforward fashion. For example, Sweden received 0.58 per cent of all the nominations, but among those nominations 1.85 per cent came from Norway, a neighbouring country. 5.26 per cent of all Swedish nominations came from Swedish scientists. That is expected. The analysis of this table, while useful in itself, makes apparent the need for some kind of normalization to remove some distorting factors. It is desirable to divide 


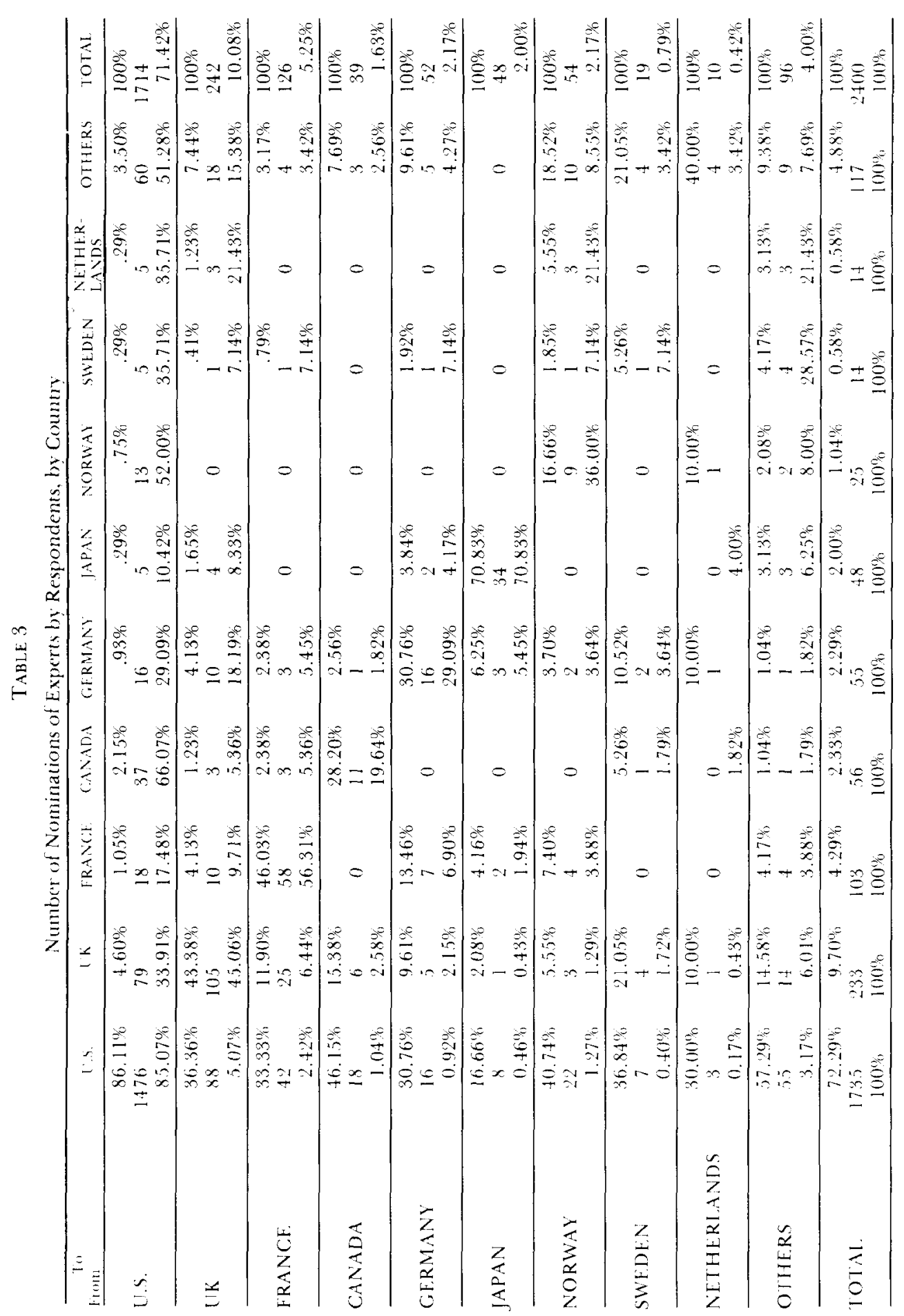







Ihe number of nominations received by the scientists in different countries over the total number of scientists in those countries. Such a relative indicator might be more representative of the influence of one scientific community upon others. It was difficule to obtain data about the number of scientists in the countries used in our study. Instead we used the number of college students in these countries, based on data in the World Handbook of Political and Social Indicators. We used these numbers as approximate estimate to the number of scientists. This way of estimating the number of scientists may be justified for countries in which growth in the number of scientists as well as in the percentage of students of science has stabilized. The data obtained are represented in Table 4. This Table has been obtained from Table 3 by the above-mentioned normalization. The total number of college students has been counted for 30 countries and it is $15,752,315$.

The upper number in cell (i, $j$ ) of Table 4 is the number of nominations received by experts in country j from nominators in country i (e.g. 79 for UK from the 1.5 . as in cell $(1,2)$ of lable 3 ) divided by our estimate of the number of scientists in the recipient country (e.g. 49,713 for UK). The lower number in cell (i, j) of Table 4 , is the same number of nominations $\mid \mathrm{e} \cdot \mathrm{g} .79$ for cell $(1,2)$ of Table $3 \mid$

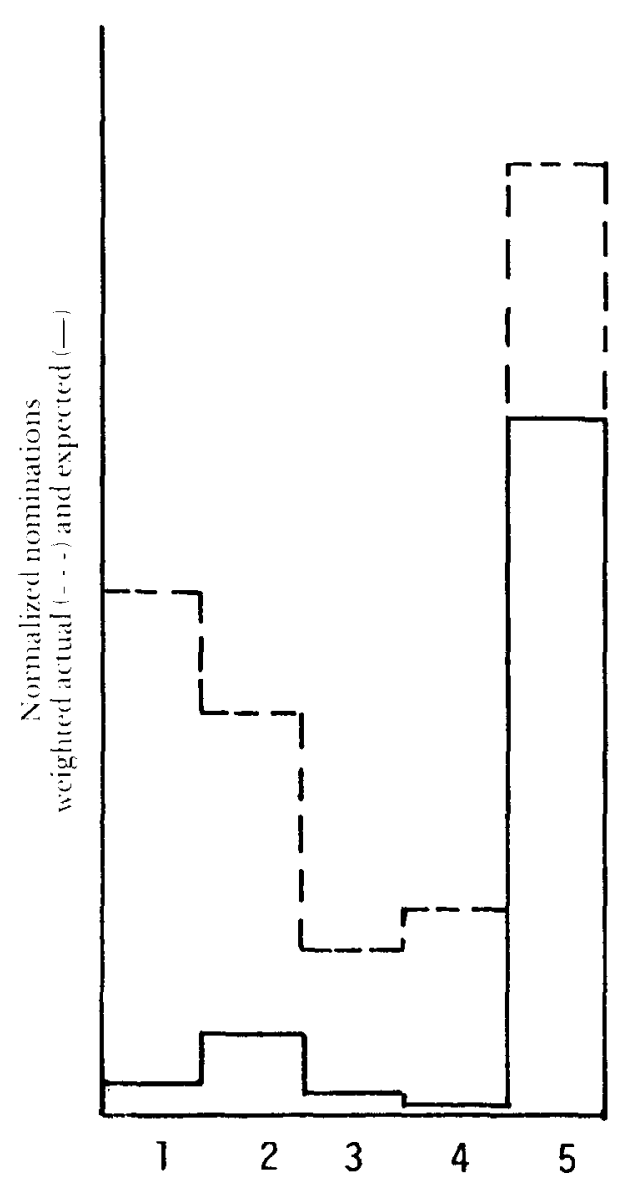

Fig. 1

Distribution of expected and actual nominations

1 - Country itsell

2 - Immediate neighbours

3 - Contincent

4 -- Same Hemisphere

5 - Opposite Hemisphere 
multiplied by the ratio of the scientific population of the country $(49,713$ for $\mathrm{UK}$ ) to the etal for all 30 countries, 15,752,315. The figures are $10^{4}$ times of the values.

From Table 1, we can see that for many countries the actual normalized nominations differ greatly from the expected ones. We can see in even more striking fashion that many respondents tend to nominate their countrymen rather than everyone else. Moreover, a large scientific or educated population does not necessarily mean that this country may expect a large number of nominations (c.g. USSR).

In Figure 1, we present a histogram reflecting the distribution of numinations aggregated by regions rather than individual countries. In the first column, we added all the normalized nominations (expected and actual) for each of the twelve coumuics itself. In the second column, we added the normalized nominations from each country to its immediate neighbours. In the third column, we added normalized nominations from each country to countries of the same continent. In the fourth column, we added all the countries in the same hemisphere. In the fifth column, we added nominations between countries in the opposite hemisphere. Onc can see a striking difference between two distributions. A chi-square test show's that the difference between the two first columns in both distributions may not be accidental. It may be statistically significant.

\section{SOME REMARKS AND CONCLUSIONS}

If there were no other factors, then the greater the distance between the nominator and the nominec, the less likely the act of nomination, up to the distance separating persons in the same continent. Surprisingly, however, experts are much more likcly to nominate one another if the distance between them is so great that they are on opposite continents. This may due to the pervasiveness of, say, the English-speaking world, but only in small measure. The main reason appears to be the predominance of the U.S., whose experts are named from the opposite hemisphere, such as Europe and Asia.

As may be anticipated, the geographical distribution of nominations has also been different inside major scientific regions. Thus, statistics for California have shown that Berkeley accounts for 101 nominations of the total 396 for California. Filteen nominations have been received by scientists from Irvine, 17 from Menlo Park, 71 from Los Angeles, 42 from San Jose, 77 from Stanford, 13 from Santa Monica, 15 from Palo Alto, 10 from La Jolla, etc. In New York State, 72 were received by New York City, 43 by Ithaca, 21 by Stonybrook, and 11 nominations went to Albany, Brooklyn and Syracuse respectively. In Michigan, Ann Arbor received 43 nominations and East Lansing received 5.

The number of nominations itself does not mean much if it is not accompanied by some understanding of the factors underlying the process. Personal face-10face contacts between scientists were more easily made when they worked in the sane neighbourhood, and could readily get together, and each is more likely to scrve as an expert for the other. With the growth of cities and their increasing lragmentation, it may no longer be so easy for scientists in the same urban area to maintain contact. When transportation costs were still affordable, a shift from contacts based on geographic proximity to contacts based on membership in the same invisible college is likely to have taken place. That is, a greater proportion of a scientist's professional contacts are likely to have occurred at scientific meetings, during travel, etc. Now that transportation costs are becoming prohibitive at the 
same time that the costs of newer forms of electronic communication are decreasing, we may see a greater proportion of contacts over these media, overcoming geographic barriers and distances. The U.S. has predominated at least in gross scientific productivity (the number of scientific publications). Again the fraction of the world's literature output due to the U.S. is decreasing, and the USSR has increased the rate at which it produces books (many of which are not scientific), so that it now leads world book production. With the current decline in U.S. science and the visibility of its science in many parts of the world, and increasing prejudice against U.S. products, U.S. predominance in nominations may be subject to change.

The drastically low number of scientific nominations to the Soviet Union could probably best be explained in terms of the serious social isolation of Soviet science. The rare appearance of Soviet scientists in international symposia makes them unable to make contacts with scientists from the outside world, and that is probably the main reason. Another plausible reason is that very few Soviet scientists work in unclassified areas where they could publish easily. It is interesting to notice that all four nominations from the USSR were to scientists in mathematical fields, which is conventionally the most open area of scientific research.

Our finding that U.S. scientists are most frequently nominated corresponds to the finding (France and Baum, 1978) that U.S. research output is more heavily cited.

The lack of nominations of Soviet scientists is visible among the western respondents as well as among the Soviet nominators themselves. Responses from the Soviet scientists arrived too late to be included in the computer data base, but when analysed separately, it has been found that they do not contain a single Soviet countryman.

As in the case of citation data, the distribution of eminence in science may shift away from the U.S. and USSR. World scientific literature is still growing exponentially, but the fastest-growing contribution comes from countries such as South Africa, Brazil, New Zealand and the newly industrialized countries. To be sure, the journals containing those contributions may be largely local rather than international. The skew distribution of countries receiving varying numbers of nominated scientists is likely to shift toward less skewness and more uniformity. That can further the growth of science if there is sufficient interaction among countries, indicated by a greater proportion of diagonal non-zero entries in the country-by-country tabulation of nominations. That would reflect more interaction than isolation.

The notion of distance on which our results are based is subject to various criticisms. First, aggregating all nominators or nominees by country does not reflect geographic distance. Norway and Sweden are neighbours and close, but the U.S. and U.S.S.R. are neighbours but not geographically proximate. The distance between Vladivostock and Anchorage is less than that between the intellectual centers of these two countries. Moreover, the intellectual center of the USSR is probably Moscow, with little variance, while the variance in the U.S. is much greater. Second, it is not so much the number of miles between respondents or nominces that matters as the time it takes to get from one site to another. Thus, two persons at separated points in Mexico City may be further apart than a person in New York from one in Washington. Two colleagues on the same floor are closer than two colleagues on different floors of the same building. Third, neighbouring countries can be in different continents, such as U.S. and USSR. 
None the less, there is probably some truth to the claim that geographic proximity, however it is defined and measured, accounts for some of the variance in who is selected as a peer.

Is that a cause for concern about the efficacy of peer review? If the most productive, eminent and competent scientists cling together, all in a small area, so that each would be geographically proximate to the others in his field, then the bias toward selecting pecers by geographic proximity would favour the efficacy of pere evaluation. Such clustering probably exists to a degrec. A question we have not addressed and which should be explored next is whether the geographical bias is present bevond what such clustering would lead us to expect. We offer the hypothesis that for the best scientists, that is not the case: if they favour nearly peers it is because these happen to be the most competent ones. For the other scientists, there may be such deviations, but it is not likely to affect the progress of science, which moves forward largely as a result of high-quality contributions from its best practitioners, being robustly insensitive to errors or deviations by others.

Acknowledgements: The authors would like to express their thanks to the National Science Foundation for their support of our research on links of interest and expertise among scientists and dynamics in the organization of scientific speriatties. Wo also gratefully acknowledge the valuable assistance of Charles Barr with data analysis and editing of the manuscript.

\section{REFERENCES}

ARFISON, P.H. (1980). Scientific commmnication. Srience, 209, 60-6?

BFAVF, 1). and PRICF, D.J. DE 5. (1966). Collaboration in an invisible college. American Psychology, 21(11), 1011-1018.

cole, je and colt, s. (1979). Which researchers will get the grant. Nature, 279.

colf, s. and colf, J. 1967). Scientific output and recognition: A study in the operation of the reward system in science. Americam Sociological Revieu, 32, 391-405.

(o) . S, S., col.t, J.R. and DIETRICH, L. (1978). Measuring the cognitive state of scientific disciplines. In: Touard a Metric of Sctence (Y. Elkana et al., eds.) 209-252. New York: Wilex.

colf, S., RLBIN, L. and cole, J.R. (1977). Peer review and the support of science. Scientific lmirican, $237,34-41$.

(ikANi, D. (1972). Inarsible Colleges: Diffusion of Knouledge in Scientific Communtites. Chicago: Iniversiur ol Chicago Press.

FroIoN, A. (1971). The need for quality filters in information systems. Sciense, 171, 133.

FAECKR, K. 1970). Report to the first general assembly on refereeing in scientilie periodicals. ELSF, Asociation of European Fditors of Biological, fournals, unpublished.

lRAME, J.D. and BAIM, J.J. (1978). Cross-national information flow's in basic rescarch: Examples taken from physics. Jourrat of the American Society for Information Science. 29 $151,2$.

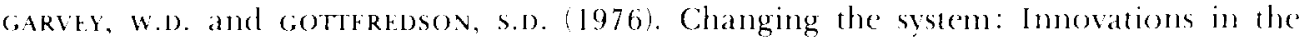
interative social system of scicntific communication. Information Processing and Hamagemem, $12(\mathrm{~N} 0.3), 165$.

GorfMAN, w. and WARREN, k.s. (1969). Dispersion of papers among journals based on a mathematical analysis of two diverse medical literatures. Nature. 221, 1205.

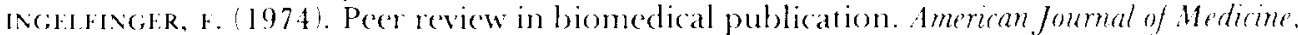
$56.686(-6992$

kADUsin, c. (1966). Friends and supporters of psychotherapy---social circles in urban life. Amerean Sorciologial Reteru, 31, 786-802. 
kadushin, G. (1974). The American Intellectual Elite. Boston: Little and Brown.

KING, D.W., MCDONAL.D, D. P., and RODERFR, N.K. (1975). Science Indicators 1974. Washingtom, D.C.: NSF.

kochr. M. (1967). The Growth of Knowledge, (ed.), New York: Wiley.

KOCHEN, м. (1974). Principles of Information Retrieval. Los Angeles: Melville/Wiley.

KOCHEN, M. and BlaIVAs, A. (1981). A model for the growth of mathematical specialties. Scientometrics. In print.

KOCHFN, M. and PERKF.I, B. (1978). Improving referee-selection and manuscript evaluation. In: Scientific Information Transfer: The Fditor's Role (M. Balaban, ed.), Dordrecht, Holland: Reidel.

Lindosey, D. (1978). The Scientific Publication System in Social Science. San Francisco: JosseyBass.

LINF, M. (1981). The structure of social science literature as shown by a large-scale citation analysis. Social Science Information Studies, 1, 67-87.

Manheim, F.T. (1973). Referees and publications crisis. Transactions of the American Geophysiral Society, $54(5), 532-537$

NOBL., J. H., JR. (1974). Peer review: Quality control of applied social research. Science, $185,916-921$.

PRICH, D.J. DE S. (1965). Network of scientific papers. Science, 149, 510-515.

PRICE, D.J. DE s. and GURSEY, s. (1979). Studies in Scientometrics I and II. Linpublished manuscripts, Yale University.

rockeFfli.er FOUNDATION. (1965). Coping with the Biomedical Explosion (K. S. Warren, ed.) New York.

TAYlor, C.L. and Hudon, M.C. (1978). World Handbook of Political and Social Indicators (Second Edition), 247-252, New Haven: Yale University Press.

zIMAN, J. M. (1978). In: Scientific information transfer: the editor's role. (M. Balaban, ed.) Dordrecht, Holland: Reidel.

zIMAN, J.M. (1980). The proliferation of scientific literature. Science, 208, 369-371.

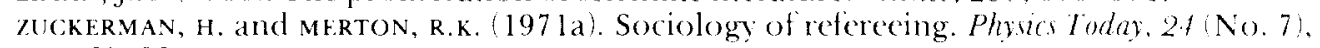
28-33.

ZUCKR.RAN, H. and MERTON, R.K. (197 lb). Patterns of craluation in science: Institutionalism, structure, and functions of the referee system. Minerta, 9, 60-100. 